\title{
EFEITO DO ETHEPHON EM VIDEIRA 'RUBI' (Vitis vinifera L.), CULTIVADA NA REGIÃO NOROESTE DO ESTADO DE SÃO PAULO'
}

\author{
ANTONIO AUGUSTO FRACARO ${ }^{2}$, APARECIDA CONCEIÇÃO BOLIANI ${ }^{3}$
}

\begin{abstract}
RESUMO- O experimento foi conduzido em vinhedo comercial da cv. Rubi, localizado na região Noroeste do Estado de São Paulo. Teve, como objetivo, verificar o efeito do ethephon, aplicado antes da poda de produção, na porcentagem de desfolhamento, tempo de realização da poda, brotação dos ramos, produção da videira, tentando reduzir os custos, melhorando a produtividade e a qualidade. Concluiu-se que a aplicação de 7500ppm de ethephon, 20 dias antes da poda, foi o tratamento que proporcionou maior porcentagem de desfolhamento, menor tempo de realização da poda, maior porcentagem de gemas brotadas e maior produção.
\end{abstract}

Termo para indexação: Uva de mesa, poda, desfolhamento, brotação, produção.

\section{EFFECT OF INCREASING ETHEPHON IN VINE 'RUBI' (Vitis vinifera L.), CULTIVATED IN THE NORTHWEST REGION OF SÃO PAULO STATE}

\begin{abstract}
The experiment was carried in commercial vineyard of cultivar Ruby, located in the region northwest of São Paulo State. Had as objective, evaluating the effect of ethephon, applied before the pruning the production, in the percentage of defoliation, time of accomplishment of the pruning, shooting of the branches, production of the grapevine, tempt to reduce costs improving the productivity and the quality. It was concluded that the $7500 \mathrm{ppm}$ the ethephon application, 20 days before the pruning, it was the treatment provide larger percentage of it defoliates, smaller time of accomplishment of the pruning, larger percentage of sprouted bud and larger production.
\end{abstract}

Index terms: Grape, pruning, defoliates, shooting, production.

As uvas de mesa em cultivo no Brasil podem ser divididas em dois grupos distintos: uvas rústicas e uvas finas. Com relação às uvas finas, cultivadas na região Noroeste do Estado de São Paulo, abrangem uma área de 1085 ha, principalmente das cvs. Itália, Rubi, Benitaka e Brasil, de alta produtividade e com frutos de boa qualidade. Devido à tecnologia desenvolvida para o cultivo na região, com condições climáticas de inverno seco e verão quente e chuvoso, com dupla poda anual de ramos lenhosos, a colheita dos frutos ocorre de junho a dezembro. Entretanto, os altos custos de implantação e de condução dos vinhedos exigem altas produtividades para tornar a atividade compensatória. A grande exigência de tratos culturais e fitossanitários, dos quais a mão-de-obra e os insumos representam em torno de 33 e 50\%, respectivamente, do custo de produção, força alguns viticultores a buscarem alternativas para reduzir este custo, entre as quais, $o$ uso de reguladores vegetais.

Verificou-se que alguns autores como Carrasquila (1991), Albuquerque \& Albuquerque (1993), Albuquerque (1996), Bautista et al. (1991), Simancas et al. (1987), trabalhando com ethephon, obtiveram bons resultados referentes à melhoria de brotação e produtividade.

Em função do exposto, foi desenvolvido este trabalho com o objetivo de verificar o efeito de diferentes concentrações de ethephon, aplicado antes da poda de produção, na porcentagem de desfolhamento, tempo de realização da poda, brotação dos ramos e produção da videira, na região Noroeste do Estado de São Paulo, tentando reduzir os custos, melhorando a produtividade e a qualidade.

O experimento foi conduzido em um vinhedo comercial da cultivar Rubi, região Noroeste do Estado de São Paulo, latitude $20^{\circ} 16^{\prime} \mathrm{S}$, longitude $50^{\circ} 33^{\prime} \mathrm{W}$ e altitude média de $483 \mathrm{~m}$.

O vinhedo foi instalado em 1990, com porta-enxerto IAC-572 'Jales', e o sistema de condução empregado foi o da "latada", no espaçamento $5 \times 3 \mathrm{~m}$ e condução das plantas na forma de "espinha de peixe".

O delineamento experimental utilizado foi o inteiramente casualizado, com quatro tratamentos e cinco repetições, sendo que uma planta constituiu uma parcela, separadas por uma planta de bordadura, e os tratamentos utilizados foram:

$\mathrm{T}_{1}$ : Testemunha - sem aplicação de ethephon

$\mathrm{T}_{2}: 3 \mathrm{~L} \mathrm{ha}^{-1}$ de ethrel (ethephon, $240 \mathrm{~g}$. $\left.\mathrm{L}^{-1}\right)-4500 \mathrm{ppm}$

$\mathrm{T}_{3}: 4 \mathrm{~L} \mathrm{ha}^{-1}$ de ethrel (ethephon, $240 \mathrm{~g}$. $\left.\mathrm{L}^{-1}\right)-6000 \mathrm{ppm}$

$\mathrm{T}_{4}: 5 \mathrm{~L} \mathrm{ha}^{-1}$ de ethrel (ethephon, $240 \mathrm{~g}$. $\mathrm{L}^{-1}$ ) $-7500 \mathrm{ppm}$

As plantas foram pulverizadas dia 15 de abril de 1997, com seus respectivos tratamentos e podados os ramos laterais com 12 gemas, vinte dias após (05 de maio), os quais apresentavam folhas maduras e bom estado fitossanitário. A aplicação do produto foi realizada com pulverizador tratorizado, modelo KO 500 litros, usando um litro de calda por planta, com aplicação até o ponto de escorrimento.

\footnotetext{
1 (Trabalho 195/2000). Recebido: 04/09/2000. Aceito para publicação: 04/10/2001. Parte da Dissertação apresentada a FE/UNESP, pelo primeiro autor, como requisito para obtenção do título de Mestre em Agronomia

2 Eng $^{\circ}$. Agr ${ }^{\circ}$., M.Sc. da ETE de Jales, Rua Dezessete n 1872, Jardim América, CEP 15.700-000 - E-mail : fracaro@melfinet.com.br- Jales-SP

3 Prof $^{a}$ Dr $^{a}$. do Departamento de Fitotecnia, Tecnologia de Alimentos e Sócio-Economia da FE/UNESP- CEP 15.385-000 - E-mail: boliani@agr.feis.unesp.br - Ilha Solteira-SP
} 
TABELA 1 - Efeito da aplicação de ethephon antes da poda de produção sobre a videira 'RUBI', cultivada na região Noroeste do Estado de São Paulo, 1997.

\begin{tabular}{lcrrrr}
\hline & \multicolumn{5}{c}{ Concentrações de ethephon (ppm) } \\
\hline Variáveis & Unidade & \multicolumn{1}{c}{0} & 4500 & \multicolumn{1}{c}{6000} & 7500 \\
\hline Porcentagem de desfolhamento & $\%$ & $4,41 \mathrm{c}$ & $12,80 \mathrm{bc}$ & $24,52 \mathrm{ab}$ & $37,74 \mathrm{a}$ \\
Tempode realização da poda & min. $1^{-1}$ & $12,45 \mathrm{a}$ & $11,74 \mathrm{a}$ & $11,92 \mathrm{a}$ & $10,50 \mathrm{a}$ \\
Porcentagem de gemas brotadas & $\%$ & $40,26 \mathrm{~b}$ & $54,16 \mathrm{a}$ & $50,35 \mathrm{ab}$ & $59,69 \mathrm{a}$ \\
Produção & $\mathrm{kg} \cdot \mathrm{pl}^{-1}$ & $59,02 \mathrm{a}$ & $40,28 \mathrm{~b}$ & $64,00 \mathrm{a}$ & $77,54 \mathrm{a}$ \\
\hline
\end{tabular}

As variáveis avaliadas foram: porcentagem de desfolhamento, tempo de realização da poda, porcentagem das gemas brotadas e produção.

Na Tabela 1, são apresentados os resultados de porcentagem de desfolhamento, tempo de realização da poda, porcentagem de gemas brotadas e produção.

\section{Porcentagem de desfolhamento}

Foi observado que, cinco dias após a aplicação do produto, as plantas que receberam o tratamento de ethephon, apresentaram início de amarelecimento das folhas, nove dias após, iniciou-se a queda e, aos quinze dias, o ramo apresentava de 80 a $90 \%$ de desfolhamento na parte acima do aramado. Desta forma, melhorou-se a visualização do ramo a ser podado e, conseqüentemente, diminuiu o tempo de realização da poda.

À medida que se aumentou a concentração do ethephon, houve aumento da porcentagem de desfolhamento.

Através da análise estatística, percebe-se o resultado altamente significativo, levando a sugerir que, através da senescência das folhas, pode ter havido uma translocação de reservas, das folhas para as gemas e posterior queda, resultando em maior brotação.

$\mathrm{O}$ efeito do regulador é notado claramente, entre a testemunha e o tratamento $4500 \mathrm{ppm}$ onde caiu $8,39 \%$, aumentando a queda entre os tratamentos $4500 \mathrm{ppm}$ e $6000 \mathrm{ppm}$ para $11,72 \%$ e de $13,22 \%$ entre os tratamentos $6000 \mathrm{ppm}$ e $7500 \mathrm{ppm}$, ou seja, conforme aumentou a concentração de ethephon, aumentou inclusive o incremento de queda de folhas. Comparando o melhor resultado $(7500 \mathrm{ppm})$, notou-se um desfolhamento de $33,33 \%$ a mais que a testemunha.

\section{Tempo de realização da poda}

Os menores tempos de realização da poda foram obtidos quando foram efetuadas as aplicações do regulador vegetal nas maiores concentrações. Tal fato pode ser atribuído ao aumento do desfolhamento das plantas pelo uso do regulador que, além de facilitar a realização da poda, possibita uma redução nos custos com a mão-de-obra. Apesar de estatisticamente não apresentar diferenças significativas, na prática, representa muita economia, ou seja, 2,7 dias de serviço de 8 horas para cada hectare tratado com 7500 ppm em relação à testemunha.

\section{Porcentagem de gemas brotadas}

Percebe-se a tendência de aumentar a porcentagem de gemas brotadas por ramo com o aumento da concentração do regulador vegetal. O tratamento $4500 \mathrm{ppm}$ apresentou maior brotação que o tratamento 6000ppm, menor número de cachos e menor produção. O regulador vegetal utilizado não aumentou a produção de forma direta, mas promoveu uma melhor brotação das gemas, aumentando a probabilidade de emitir cachos, uma vez que a presença de cacho é inerente à própria planta. Utilizado em maiores concentrações, o ethephon favoreceu a produção.

Outra prática comum entre os produtores é a realização da torção (massagem) dos ramos para melhorar a brotação. O tempo gasto com esta operação pode ser economizado com o uso do regulador vegetal, pois observou-se que, com o aumento da concentração do produto, ocorreu aumento na brotação das gemas, dispensando, assim, esta prática. Portanto, com o uso de $7500 \mathrm{ppm}$ de ethephon, o produtor deixa de gastar 8,6 dias de serviço com a torção e 2,7 dias com a realização da poda, totalizando 11,3 homens-dia por hectare, quando comparado à testemunha.

\section{Produção}

Na Tabela 01, podem-se observar os dados referentes à produção média, apresentado em quilos por planta. Observouse que houve um aumento na produção, em relação à testemunha, quando se utilizou-se o ethephon nas concentrações $6000 \mathrm{e}$ $7500 \mathrm{ppm}$.

A concentração de $4500 \mathrm{ppm}$ de ethephon diminuiu a produção, quando comparado com a testemunha. Para tal comportamento, não foi encontrada nenhuma explicação.

Em números absolutos, a diferença de $18,52 \mathrm{~kg} \mathrm{pl}^{-1}$ entre os tratamentos $7500 \mathrm{ppm}$ e a testemunha é considerável, permitindo ao produtor um ganho de $\mathrm{R} \$ 16,70 \mathrm{pl}^{-1}$ (considerando, $\mathrm{R} \$ 0,90 \mathrm{~kg}$ ${ }^{1}$ ), ou seja, em torno de R $\$ 11100,00 \mathrm{ha}^{-1}$. Portanto, se observarmos a Tabela 01, percebe-se com clareza o incremento da produção com o aumento da concentração de ethephon.

É importante salientar que a produção da testemunha foi acima da média da região e somente os melhores produtores conseguem obter estas produtividades. Verificou-se que a utilização do ethephon aumentou em até $31,38 \%$ a produção, obtendo-se 51641,64 kg ha-1 , já descontado o custo de aplicação e do produto.

A aplicação de ethephon, na concentração de 7500ppm, 20 dias antes da poda, proporcionou maior porcentagem de desfolhamento, menor tempo de realização da poda e maior porcentagem de gemas brotadas.

O uso do ethephon, na maior concentração, aumentou a produção em até $31,38 \%$. 


\section{REFERÊNCIAS BIBLIOGRÁFICAS}

ALBUQUERQUE, T.C.S., ALBUQUERQUE, J.A.S. Pesquisas desenvolvidas para melhorar a brotação da videira na região semi-árida brasileira. Petrolina: CPATSA - EMBRAPA, 1993. 7p. (Circular técnica, 79).

ALBUQUERQUE, T.C.S. Uva para exportação: aspecto técnico da produção. Brasília: EMBRAPA, 1996. 53 p. (Publicações técnicas FRUPEX, 25).
BAUTISTA, A.D, VARGAS, G., COLMENARES, J.C. Influencia del etefon sobre la brotacion y fertilidad de tres cultivares de vid. Agronomia Tropical, Maracay, v. 41, n. 5-6, p. 225-35, 1991.

CARRASQUILLA, E. Hidrogen cyanamide increases grapevine yield. Notícias-Agrícolas, Caracas, v.12, n. 14, p. 108-11, 1991.

SIMANCAS, R.; CORZO, P; BRACHO, E. Evaluation of different methods to improve budbreak in tropical vineyards. ActaHorticulturae, Wageningen, n. 199, p. 90, 1987. 